\title{
Screening of endophytic microorganisms from sweetpotato for the production of antimicrobial compounds
}

\author{
Julie D. Tan', Edmundo L. Sanchez, Jr.', Michiko Tanaka², Taiki \\ Katayama' ${ }^{2}$ Kozo Asano ${ }^{2}$, and Fusao Tomita ${ }^{2}$ \\ 'Philippine Rootcrop Research and Training Center, Visayas State University \\ (formerly Leyte State University), Baybay City, Leyte 6521-A, Philippines; \\ 'Laboratory of Applied Microbiology, Faculty of Agriculture, Hokkaido University, \\ Sapporo 060 Japan
}

\begin{abstract}
This study was an attempt to isolate endophytic microorganism with antimicrobial properties from sweetpotato that are grown in the Philippines. Endophytic microorganisms were isolated from surface-sterilized stem cuttings of selected Philippine sweetpotato varietles such as BSP-SP-17, BSP-SP-22, and NSIC-SP-25. The isolates were purified and tested for antimicrobial activities using spot and streak inoculation methods against Lasiodiplodia theobromae (sweetpotato rot-causing mold), Colletotrichum gloeosporioides (yam anthracnose-causing mold), Diplodia natalensis (watermelon and citrus stem end rot-causing mold), and Bacillus subtilis (potato soft rot-causing bacteria). Twenty-one isolates ( 12 bacteria and 9 fungi) exhibited antimicrobial activities against one or more indicator microorganisms tested. The bacteria were identified through 16S rDNA sequencing analyses as Bacillus megaterium, Bacillus pumilus, Microbacterium arborescens, Micrococcus luteus and Bacillus subtilis. The fungi were also identified through their partial 26S rDNA and ITS region sequencing analyses as Phomopsis sp., Aspergillus sp., Penicillium sp. and two belong to Mycosphaerellaceae and Polyporaceae family respectively. The supernatant of these isolates were further tested against the above four indicator microorganisms and four other types of indicators such as B. subtilis AHU 2035, A. flavus var. asper AHU7051, Alternaria sp. S-1 and $C$. albicans CAI4. All identified isolates possessed wide spectrum of activity against the indicator microorganisms. B. subtilis, B. megaterium, Penicillum sp. and one isolate belonging to Mycosphaerellaceae family were able to inhibit 6 or more of the indicator microorganisms tested.
\end{abstract}

Keywords: sweetpotato, endophytes, zone of inhibition, bacteria, fungi, screening

Correspondence: J. D. Tan Address: Philippine Rootcrops Research and Training Center, Visayas State University, Baybay City, Leyte, 6521-A. Philippines. Email. jdiamantetan@yahoo.com Tel. No. (053) 335-2616

DOI: $10.32945 /$ atr2924.2007 


\section{INTRODUCTION}

The beneficial role of endophytic microorganisms which are found in a wide range of plants and plant tissues has been extensively studied by various researchers. The isolation of endophytes is mostly done in temperate regions but recently, endophytic mycobiota of topical ecosystems have been investigated. It is believed that with hot and moist climate, a very rich flora of endophytic fungi can be found (Carrol, 1990).

Endophytes are usually fungi or bacteria, which grow symbiotically inside the plant tissues. Virtually, wide spectrum of interactions is involved between endophytes and plant hosts. However, the asymptomatic or beneficial effects of endophytes in host plants are mostly emphasized in various researches. Their growth does not lead to any pathogenic symptoms in plants. These microorganisms are found to increase the plant vigor, drought tolerance, resistance to predation and diseases and ability to withstand other stresses (Latch, 1994). Consequently, the growth and proliferation of endophytic microorganisms in agricultural plants lead to an increase in crop yield. Moreover, endophytes are increasingly recognized as a group of microorganisms that could provide new secondary metabolites that are useful in biotechnology and agriculture (Bills and Polyshook, 1992).

Alkaloid compounds, which act as natural insecticides within the plants, are secreted by endophytes (Emerald Seed and Supply, 2001). Antibiotic compounds are also produced by endophytes from ericaceous plants (Fisher et al., 1984). Secondary metabolites with broad antifungal activity are likewise produced by endophytic strain of Cryptosporiopsis (Noble et al., 1991). An anti-cancer drug called taxol was also reported as an important compound by produced by endophytic fungi such as Taxomyces andreanae, Pestalotia, Pestalotiopsis, Fusarium, Alternaria, Pithomyces and Monochaetia (Strobel et al., 1996).

The Philippine Root Crop Research and Training Center (PhilRootcrops) at the Visayas State University, Baybay, Leyte has developed high-yielding and appropriate varieties of sweetpotato for specific uses. At present, the problem of non-resistance of these hybrid varieties to pests and diseases has not been fully addressed. These developed varieties generally possess special characteristics that are suitable for processing of food products but are found 
to be susceptible to pests and diseases. Thus, supply of raw materials becomes limited and production of processed products is also hampered. While PhilRootcrops is equally engaged in developing varieties that are highly resistant to pests and diseases, the control of these pests and diseases is also one of the priority goals for the Center. In this study therefore, the endophytic microorganisms from selected varieties of sweetpotato were collected, identified and screened for production of antimicrobial compounds against some selected indicator microorganisms, most of which are disease-causing microorganisms in rootcrops.

\section{MATERIALS AND METHODS}

\section{Collection and preparation of samples for microbial analysis}

Branches of sweetpotato plants were collected and used in this study. The plant samples were washed in running water for 10 minutes and branches were cut in $1 \mathrm{~cm}$ length ad surface-sterilized by dipping in $75 \%$ ethanol for 1 minute then dipped in 5.3\% sodium hypochlorite solution for 5 minutes and finally dipped in $75 \%$ ethanol for 0.5 minutes. The treated samples were dried and cut into halves in sterilized slides under the clean bench and mounted on nutrient agar (NA) and potato dextrose agar (PDA) plates. Incubation was done from 3 days to 3 weeks at $27^{\circ} \mathrm{C}$ or until abundant growth of bacteria and fungi appeared. Bacteria and fungi that grew from underneath the samples that were incubated unto the agar were transferred in NA and PDA slants respectively and incubated at $27^{\circ} \mathrm{C}$. All isolates were purified using serial dilution method and distinct single colonies were pick out from the agar plate and transferred into the agar slant. The purity of the isolates grown in agar was confirmed through microscopic examination.

\section{Testing of anti-microbial activities of the isolates}

All isolates were tested for their antimicrobial activities using spot and streak inoculation methods against the indicator microorganisms such as Lasiodiplodia theobromae (SP rot-casuing mold), Colletotrichum 
gloeosporioides (yam anthracnose-causing mold), Diplodia natalensis (watermelon and citrus stem end rot-causing mold), and Bacillus subtilis (potato soft rot-causing bacteria). In spot inoculation method, the test and indicator microorganisms were inoculated side-by-side $3 \mathrm{~cm}$ apart in the plate agar. Positive inhibition is demonstrated by negation of growth of indicator microorganisms. In streak plate method, the test organism was streaked perpendicularly across the indicator microorganisms and inhibition of growth of indicator microorganisms at the intersection showed positive activity. Other indicator microorganisms such as Bacillus subtilis AHU 1035, Candida albicans CA14, Aspergillus flavus var. asper AHU 7051 and Alternaria sp. S-1 were used in screening further the isolates the exhibited positive activities against $L$. theobromae, $C$. gloeosporioides, D. natalensis, and B. subtilis using the supernatant of test microorganisms. The bacteria were grown in Nutrient Broth for 1-2 days while fungi were grown in Potato Dextrose Broth with Yeast Extract and Malt Yeast Extract Broth for 2-3 days. The bacteria and fungi were grown in their respective media and the supernatant were assayed for biological activity against the above indicator microorganisms.

\section{Identification of the isolates}

The isolates with positive activities against one or more test microorganisms were characterized taxonomically through $16 \mathrm{~S}$ rDNA (bacteria) and partial 26S rDNA and ITS (internal transcribed space) region (fungi) sequencing analyses. For the sequence analysis, bacterial and fungi DNA were extracted using ISOPLANT (Nippon gene). The genes of $16 \mathrm{~S}$ rRNA, partial 26S RNA and ITS region including 5.8S rRNA were amplified using primer pairs of $27 \mathrm{~F}$ (5'-AGAGTTTGATCCTGGCTCAG-3')-1522R ( $5^{\prime}$ - G G C T A C C T T G T T A C G A C T - 3'), N L I ( 5 ' GCATATCAATAA GCGGA GGAAAA G - 3') - N L 4 (5' GGTCCGTGTTTCAAGACGG-3') and ITS4-ITS5-3') respectively in the following conditions $\left(2.5 \mathrm{~min}\right.$ at $95^{\circ} \mathrm{C}, 30$ cycles of $30 \mathrm{~s}$ at $94^{\circ} \mathrm{C}, 1 \mathrm{~min}$ at $50^{\circ} \mathrm{C}$ and $1 \mathrm{~min}$ at $72^{\circ} \mathrm{C}$ and one final step of $5 \mathrm{~min}$ at $72^{\circ} \mathrm{C}$ for bacteria, $3 \mathrm{~min}$ at $95^{\circ} \mathrm{C}, 35$ cycles of $30 \mathrm{~s}$ at $95^{\circ} \mathrm{C}, 30 \mathrm{~s}$ at $53^{\circ} \mathrm{C}$ and $2 \mathrm{~min}$ at $72^{\circ} \mathrm{C}$ and one final step of $10 \mathrm{~min}$ at $72^{\circ} \mathrm{C}$ for fungi). The amplified products were re-amplified using the following primers; (27F, 357F (5'-CTACGGGAGGCAGCAG-3'). 520R (5'-ACCGCGGGGTGCTGGC-3'), 920F (5'-AAACTCAAAGGAA 
Table 1. Types and number of microorganisms isolated from some selected varieties of sweetpotato

\begin{tabular}{lccccc}
\hline $\begin{array}{c}\text { Sweetpotato } \\
\text { Varieties }\end{array}$ & Number of Isolates & $\begin{array}{c}\text { Total Number of Isolates } \\
\text { With Biological } \\
\text { Activities* }\end{array}$ & $\begin{array}{c}\text { Total } \\
\text { Number of } \\
\text { isolates } \\
\text { With } \\
\text { Biological } \\
\text { Activities }\end{array}$ \\
\cline { 2 - 4 } & Bacteria & Fungi & Bacteria & Fungi & 7 \\
\hline BSP-SP-17 & 24 & 11 & 5 & 2 & 6 \\
BSP-SP-22 & 18 & 8 & 3 & 3 & 8 \\
NSIC-SP-25 & 25 & 10 & 4 & 4 & 21 \\
Total & 67 & 29 & 12 & 9 & \\
\hline
\end{tabular}

*Total number of isolates with biological activities against one or more indicator microorganisms such as B. subtilis, Colletotrichum gloespoiroides, Lasiodiplodia theobromae and Diplodia natalensis in spot and streak inoculation.

TTGACGG-3'), 1080R (5'-CCCAACATCTCACGAC-3') AND 1522R for the $16 \mathrm{~S}$ rDNA and NL1, NL4, ITS4, ITS5 for the partial 26S rDNA or ITS region and the ABI PRISM BigDye Terminator Cycle Sequencing Ready Reaction Kit (Applied Biosystems) containing fluorescent dye. An extension reaction was carried out by PCR following the procedure recommended by the manufacturer. The fragments were sequenced in both directions using an ABI PRISM 3100 DNA Sequencing System according to the manufacturer's instructions. To identify the isolates, the sequences obtained were complied and compared with those in the GenBank databases through the National Center for Biotechnology Information $(\mathrm{NCBI})$ using the basic linear alignment of sequences tool (BLAST; Altschul et al., 1990).

\section{RESULTS AND DISCUSSION}

Endophytic microorganisms were isolated from sweetpotato plant. Table 1 presents the type and number of isolates collected from some selected varieties of sweetpotato. A total of 96 isolates from branches of sweetpotato (var. BSP-SP-17, BSP-SP-22, and NSIC-25) were cultured and purified. Bacteria were found to be in greater number compared with fungi. Twentyone isolates were observed to possess antimicrobial activities against one or 
Table 2. Biological activities of isolates against the indicator microorganisms using spot and streak inoculation

\begin{tabular}{|c|c|c|c|c|}
\hline \multirow[t]{2}{*}{ Isolates(Code) } & \multicolumn{4}{|c|}{ Spot/Streak Inoculation } \\
\hline & A & B & $\mathbf{C}$ & D \\
\hline \multicolumn{5}{|l|}{ Bacteria } \\
\hline $17114(01)$ & - & - & + & - \\
\hline $17132(02)$ & + & - & - & - \\
\hline 1721(03) & - & + & + & - \\
\hline $17134(04)$ & + & - & - & - \\
\hline $1722(05)$ & - & + & + & - \\
\hline $223211(06)$ & - & + & - & - \\
\hline $223212(07)$ & - & + & - & - \\
\hline $2211(08)$ & - & - & + & - \\
\hline 2532(09) & - & + & + & + \\
\hline $25133(10)$ & + & - & - & - \\
\hline $25131(11)$ & + & - & - & - \\
\hline $2531(12)$ & $+/-$ & + & + & + \\
\hline \multicolumn{5}{|l|}{ Fungi } \\
\hline 1723(13) & + & + & + & - \\
\hline $172212(14)$ & - & - & + & - \\
\hline $2212(15)$ & + & - & - & - \\
\hline $22312(16)$ & + & - & - & - \\
\hline $22334(17)$ & + & - & - & - \\
\hline $25132(18)$ & + & - & - & - \\
\hline 2513(19) & - & - & + & - \\
\hline $25122(20)$ & - & - & + & - \\
\hline $25322(21)$ & + & - & - & - \\
\hline
\end{tabular}

Note: With inhibitory activity (+); Without inhibitory activity (-); Slightly clear zone of inhibition (+/-)B. subtilis (A); Colletotrichum Gloespoiroides (B); Lasiodiplodia theobromae (C); Diplodia natalensis (D). 


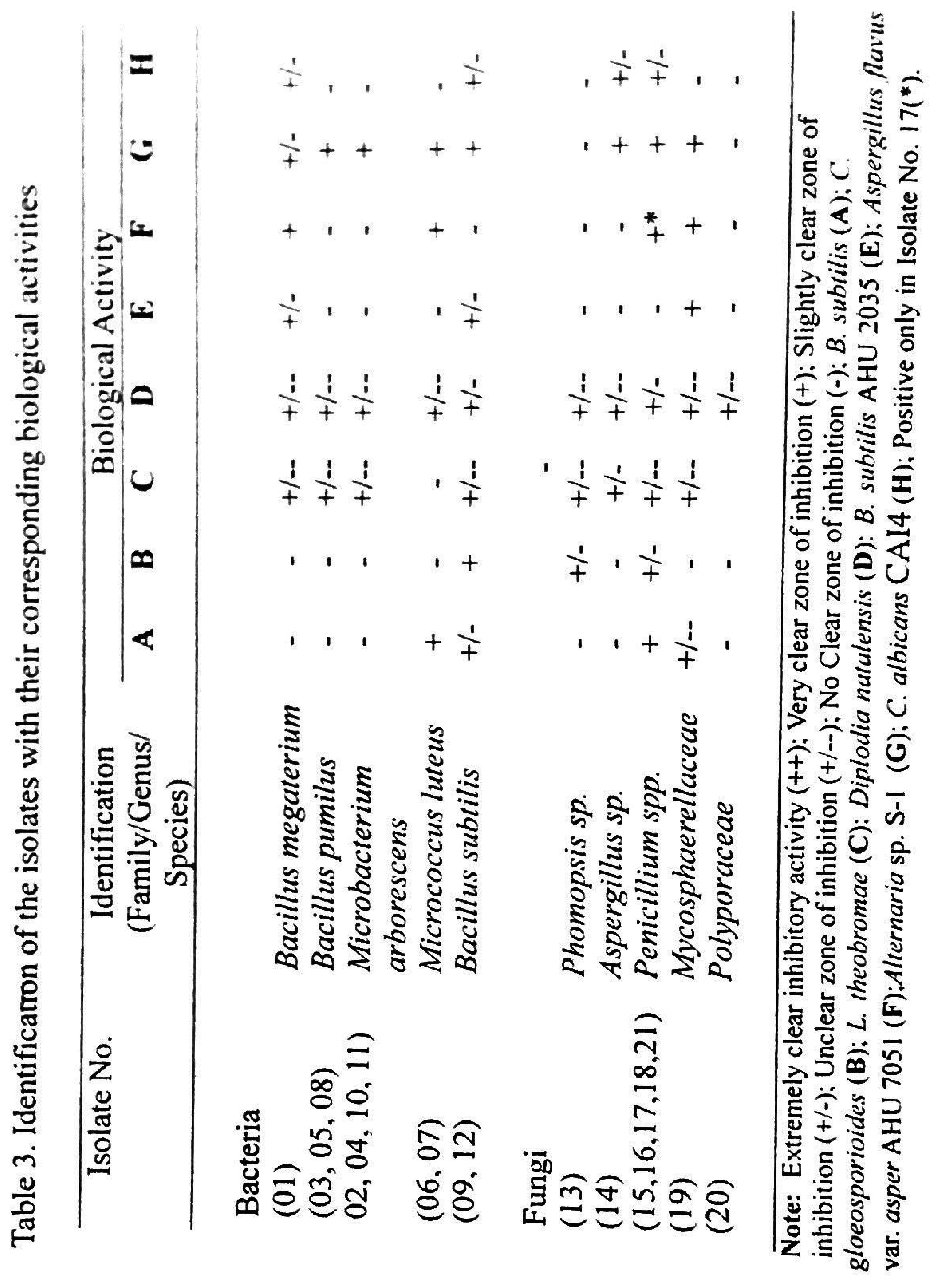


more indicator microorganisms tested using spot and streak inoculation. There were 12 bacteria and 9 fungi isolates that exhibited inhibitory growth zones in agar seeded with one or more indicator microorganisms. Majority of the isolates were able to inhibit the growth of only one or two indicator microorganisms except isolates 09,12 and 13 which inhibited 3 or almost all indicator tested. These isolates were able to inhibit C. gloeosporioides and L. theobromae.

The bioactive components produced by these isolates were further screened by testing their supernatant against the indicator microorganisms used in spot and streak inoculation and four other types of indicators such as $B$. subtilis AHU 2035, A. flavus var. asper AHU 7051, Alternaria sp. S-1 and C. albicans CAI4. Table 3 summarizes the biological activities of the 21 isolates, which produce bioactive compounds and their corresponding family or genus/species identification. Taxonomic identification of the isolates through DNA sequencing analysis showed that of the 21 isolates, only 5 were identified up to species level as exhibited by their $100 \%$ homology with those in the GenBank databases through NCBI using BLAST. These isolates were Bacillus megaterium (01), Bacillus pumilus $(03,05,08)$, Bacillus subtilis $(09,12)$. The other isolates which were characterized up to genus level only were Pkosmopsis sp. (13), Aspergillus sp. (14), Penicillium spp. (15, 16, 17 , 18, 21), Mycosphaerellaceae (19) and Polyporaceae (20). Isolates 09 and 12 consistently exhibited wide range of activity spectra. Notably, $B$. megaterium, B. subtilis, Penicillium spp. and one isolate from the Mycosphaerellaceae family exhibited wide range of activity spectra. All of these isolates were able to inhibit at varying degrees, $L$. theobromae, $D$. natalensis and Alternaria sp. S-1. Penicillium sp. and Mycosphaerella can also inhibit the growth of $B$. subtilis and A. flavus var. asper AHU 7051 while Penicillium and B. subtilis can also inhibit C. gloeosporioides and $C$. albicans to a lesser degree. Interestingly, the identified $B$. subtilis was observed to produce a compound that could inhibit the growth of the same species, $B$. subtilis AHU 1035. Other fungal isolates belonged to Aspergillus, Phomopsis sp. and Polyporaceae family and other bacterial isolates were identified as $B$. pumilus, Microbacterium arborescens and Micrococcus luteus. These isolates also exhibited inhibitory activity against D. natalensis. Generally, all the identified isolates possessed inhibitory activities against two or more indicator microorganisms tested.

The isolation of culturable endophytic microorganisms with antimicrobial activities from sweetpotato plant is suggestive of various types of microbial 
interactions and production of various types of substances inside the plant. Three species of Bacillus, namely, Bacillus megaterium, Bacillus pumilus, and Bacillus subtilis, were characterized and identified. B. subtilis, and occasionally $B$. megaterium, B. cereus, $B$. pumilus, and $B$. polymixia have the characteristics of high thermal tolerance, rapid growth in liquid culture, ready formation of resistant spores, and are considered to be safe biocontrol agents and have high potential to be used as biocontrol agents (Shoda, 2000).

The use of the gram-positive Bacillus species as a biocontrol agent has been relatively rare and has been studied less intensively than that of the gramnegative bacteria. B. subtilis which acts on the competitive exclusion principle by occupying the identical ecological niche within the plant has been used as biological control agent against Fusarium moniliforme in maize Bacon et al., 2001). Due to its high thermal tolerance, Bacillus subtilis was able to grow and proliferate in sweetpotato plant that grows in tropical countries like the Philippines.

Fungal isolates belonging to Phomopsis, Aspergillus, Penicillium spp. and Mycosphaerellaceae and Polyporaceae family were also found in sweetpotato plant. Penicillium spp. (Figure 1) and isolate identified to be a member of Mycosphaerellaceae family exhibited wide spectrum of activities against the indictor microorganisms tested. Phomopsis sp., an endophyte from leaves of Aspidosperma tomentosum and twigs of Spondias spombin has also been reported to exhibit activity against bacteria such as $E$. coli and $P$. aeruginosa; yeast such as $C$. albicans and $S$. cerevisiae and fungi such as Aspergillus niger and Fusarium oxysporum (Corrado et al., 2004). Phomopsis sp. originating from twigs of Salix graclostyla var. melanostachys produced a novel cytochalasan called Phomopsichalasin, which showed antimicrobial activities against Bacillus subtilis, Staphylococcus aureus, Salmonella gallinarum, and Candida albicans (Tan and Zou, 2001). In Tuscany, species of Aspergillus, a fungal endophyte from grapevine, Vitis viniferia, has been tested to be an antagonist of Plasmopara viticola, a pathogen of grapevines that cause lesions on leaf tissues and "oily spot" symptoms (Musetti et al., 2003).

Generally, all the identified isolates possessed inhibitory activities against two or more indicator microorganisms tested. Interestingly, majority of the isolates were able to inhibit the growth of pathogenic microorganisms that are associated with rootcrop diseases. It is no doubt therefore, that such endophytes 

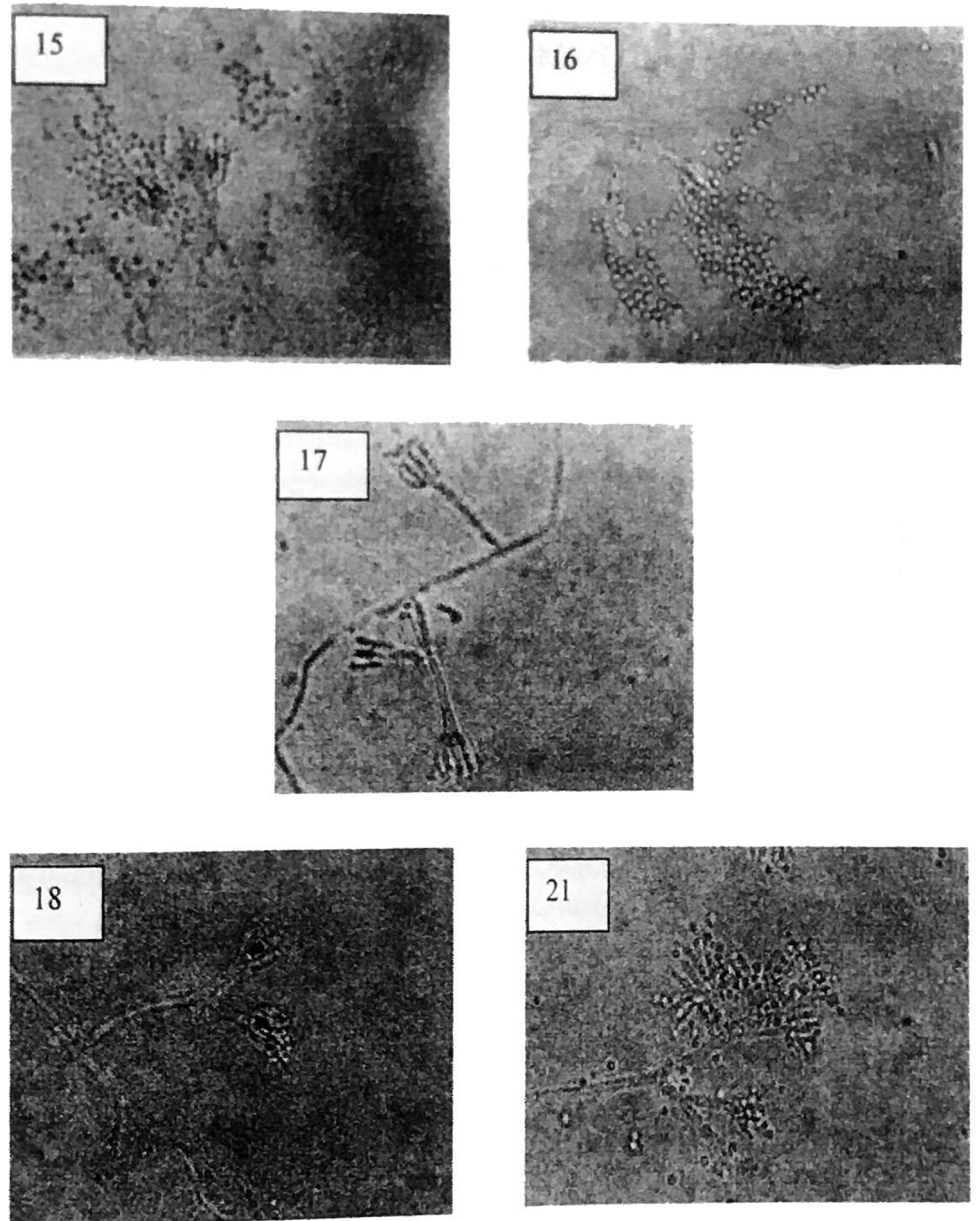

Figure 1. Penicillium species with wide spectrum of activities 
can contribute a clear solution in eradicating some important diseases in rootcrops.

\section{CONCLUSION AND RECOMMENDATION}

Endophytic microorganisms which were tested to possess inhibitory activities against some selected disease-causing microorganisms in plants especially in rootcops were identified as Bacillus megaterium, Bacillus pumilus, Microbacterium arborescens, Micrococcus luteus, Bacillus subtilis, Phomopsis sp. Aspergillus sp. Penicillium sp., Mycosphaerellaceae and Polyporaceac family. It is believed that the supernatants of these endophytes contain antimicrobial compounds that are responsible for inhibiting the indicator microorganisms. It is therefore recommended to purify and identify specific compounds that cause growth inhibition of disease-causing microorganisms for their practical applications in rootcrops and possibly in other important agriculture products in the tropical countries like the Philippines.

\section{LITERATURE CITED}

ALTSCHUL, S. F., W. GUSH, , W. MILLER, , E. W. MYERS, and D. J. LIPMAN. 1990. Basic local alignment search tool. J. Mol. Biol. 215: 403-410.

BILLS, G. F. and J. D. POLYSHOOK. 1992. Recovery of endophytic fungi from Chamaecyparis thyoides. Sydowia 14:1-12.

BACON, C. W., I. E. YATES, D. M. HINTON, and F. MEREDITH. 2001. Biological control of Fusarium moniliforme. Environmental Health Perspectives 9(2):325332.

CAROLL, G C. 1988. Fungal endophytes in stems and leaves from latent pathogen to mutualistic symbiont. Ecology 69:2-9.

CAROLL, G. C. 1990. Fungal endophytes in vascular plants: Mycological research opportunities in Japan. Trans. Mycol. Soc. Japan. 31:103-116.

CORRADO, M. and K. T. RODRIGUES. 2004. Antimicrobial evaluation of fungal extracts by endophytic strains of Phomopsis sp. J. Basic Microbiol. 44 (2):157-60.

EMERALD SEED AND SUPPLY. 2001. Endophyte. 9330 N. E. Halsey. Portland. OR 97220. 
GREENSHARE FACTSHEETS. 1999. Endophyte-enhanced grasses. Published by the University of Rhode Island Landscape Horticulture Program. USA.

FISHER, P. J., A. E. ANSON. and O. PETRINI. 1984. Antibiotic activity of some endophytic fungi from ericaceous plants. Bot. Helv. 94:249-253.

JUMPPONEN, A. and J. M. TRAPPE. 1998. Dark-septate root endophytes: A review with special reference to facultative biotrophic symbiosis. New Phytologist 140:295-310.

LAMBERT, B., F. LEYNES, , L. VAN ROOYEN, , F. GOSSELE, , Y. PAPON, and J. SWING 1987. Rhizobacteria of maize and their fungal activities. Appl. Environ. Microbiol. 53:1866-1871.

LATCH, G. C. 1994. Influence of Acremonium endophytes on perennial grass improvement. New Zealand J. Agr. Res. 37:311-318.

MAHMUT, T., S. H. MANTELL, and C. AINSWORTH. 1992. Endophytic bacteria expressing beta-glucuronidase cause false positives in transformation of Dioscorea species. Plant Cell Reports 11:452-456.

MAURHOFER, M., C. KEEL, U.SCHNIDER, C. VOISARD, D. HAAS, and G DE FAGO. 1992. Influence of enhanced antibiotic production in Pseudomonas fluorescens strain CHAO on its disease suppressive capacity. Phytopathology 82:190-195.

MUSETTI. R., L. STRINGHER, S. BORSELLI,A. VECCHIONE, F. DE LUCA, L. ZULINI, and I. PERTOT. 2003. Ultrastructural analysis Vitis vinifera leaf tissues sowing atypical symptoms of downy mildew. J. Plant Pathology 85(4, Special Issue):275320.

NOBLE, M. H., D. LANGLEY, P. J. SIDEBOTTOM, S. J. LANE, and P. J. FISHER. 1991. An ecainocandia from an endophytic Cryptosporiopsis and Pezicula sp., P. sylvestris and F. sylvatica. Mycol. Res. 95:1439-1440.

OMAFRA TURFGRASS SERIES. 1997. Debunking endophytes. Published by the University of Rhode Island Landscam. pe Horticulture Program. USA.

PIRTTILA, A. M. M. N. 2001. Endophytes in the buds of Scots pine (Pinus sylvestris L.). Academic Dissertation to be presented with the assent of the Faculty of Science, University of Oulu, Department of Biochemistry, Kuusamonsali, Linnanmaa, Oulu, Finland.

RADU, S., C. Y. KQUEEN, M. I. A. KARIM, M. SUTO, M. TANAKA, and F. TOMITA. 2001. Endophytic fungi prospecting from medicinal plants in Malaysia for useful substances. Paper presented during the BIOTEC Annual Meeting: Microbial Genetics and Microbial Diversity in Southeast Asia, November 7-10, 2001, Queen Sirikit National Convention Center, Bangkok, Thailand.

SHODA, M. 2000. Review: Bacterial control of plant diseases. J. Biosc. Bioeng. 89(6): 515-521. 
STURZ, A. V., B. R. CHRISTIE, and J. NOWAK. 2000. Bacterial endophytes: Potential role in developing sustainable systems of crop production. Critical reviews in Plant Sciences 19(1): 1-30.

STROBEL, G A., W. M. HESS, E. FORD, R. S. SIDHU, and X. YANG 1996. Taxol from fungal endophytes and the issue of biodiversity. J. Ind. Microbiol. 17:417-423.

TAN, R. X. and W. X. ZOU. 2001. Endophytes: a rich source of functional metabolites. J. The Royal Society of Chemistry. 18:448-459.

TANAKA, M., H. SUKIMAN, M. TAKEBAYASHI, K. SAITO, M. SUTO, T. K. PRANA, M. S. PRANA, and F. TOMITA. 1999. Isolation, Screening and Phylogenetic identification of endophytes from plants in Hokkaido Japan and Java Indonesia. Microbes and Environments. 14(4):237-241.

TOMITA, F., M. TANAKA, T. SONE, M. NARA, M. SUTO, A. YOKOTA, and K. ASANO. 2001. Endophytic fungi isolated from Ulmus davidiana and their association with the host plant. Paper presented during the BIOTEC Annual Meeting: Microbial Genetics and Microbial Diversity in Southeast Asia, November 7-10, 2001, Queen Sirikit National Convention Center, Bangkok, Thailand.

WHITE, T. J., T. BRUNS, S. LEE, and J. TAYLAR. 1990. Amplification and direct sequencing of fungal ribosomal RNA genes for phylogenetics, p. 315-322. In: PCR Protocols: a guide to methods and applications. Academic Press, New York. 